Cilt/Volume:11 Sayı/Issue:1 Ocak/January 2019

Araştırma Makalesi / Research Article

\title{
Estimation of Seismic Response of R/C Frame Structures to Vertical Earthquake Motion Considering Fixed Support and Soil-Structure- Interaction (SSI)
}

\author{
Selçuk Baş ${ }^{* 1}$ iD \\ ${ }^{1}$ Department of Civil Engineering, Faculty of Engineering, Bartin University, 74100 Bartin, TURKEY
}

Başvuru/Received: 13/11/2018

Kabul/Accepted: $23 / 11 / 2018$

Son Versiyon/Final Version: 31/01/2019

\begin{abstract}
The present study aims to demonstrate the effects of vertical earthquake excitation on reinforced concrete (R/C) frame structures incorporating the approaches of Soil-Structure-Interaction (SSI) and rigid foundation. Three earthquake time-histories are regarded to properly elucidate this effect. For the linear time-history analysis (LTHA), finite element model (FEM) of a highrise existing R/C structure designed according to Turkish Seismic Code (TSC, 2007) is developed. For the SSI analysis, the Direct Method (DM) is utilized instead of separated FEM (the Substructure Method). The comparative study is carried out between the SSI and the fixed support (FS) model under both only horizontal (H) and horizontal+vertical (HV) seismic motions. The difference between only $\mathrm{H}$ and $\mathrm{H}+\mathrm{V}$ load cases on the basis of the considered parameters showed that vertical earthquake motion was determined not to be effective on the base shear force, and that the SSI model could be recommended to be taken into account for analysis due to resulting higher change than the FS. Noticeable increase in the overturning moment revealed that vertical load bearing elements required more bending moment capacity. The percentage increase in the base axial force is resulted as higher under $\mathrm{H}$ load than $\mathrm{H}+\mathrm{V}$ load, which means that vertical seismic motion treats as balancing effect. Such a lower change under $\mathrm{H}+\mathrm{V}$ load case is directly pertinent to damping properties of the soil media. Therefore, the columns and piers are recommended to be designed against axial force with more safety according to the outcomes from the FS model.
\end{abstract}

\section{Key Words}

"vertical earthquake motion, soil-structure interaction, fixed support system, direct method, finite element method" 


\section{INTRODUCTION}

Seismic analysis of civil structural systems is one of the most challenging issues in the field of structural earthquake engineering due to the complexity of seismic motions. Over the last decades, certain advanced procedures for not only analysis methods but also retrofitting techniques have been continued to be developed by many researchers and the design codes (ASCE, 2007; ASCE, 2010; ASCE, 2014; Eurocode-8, 1998; IS: 1893, 2000; NBC105, 1994; NZS1170.5, 2004; TSC, 2007; UBC, 1997). In order to develop sophisticated analysis methods/design procedures, it is also essential to have reliable information for the structural behavior of load-bearing frame systems. In the seismic design stage, structural system is commonly considered to be subjected to only lateral load under earthquake motion due to high value of horizontal components of earthquakes. Vertical earthquake motion, therefore, is generally adopted in many design codes as either certain times of the horizontal component with $\mathrm{a}_{\max }$ value or not required. This assumption is generally based on that structural elements designed under vertical service loads (dead, live etc.) have high capacity for vertical motion. In other words, vertical ground motion can be safely carried by structural system due to high vertical strength capacity of structural elements. However, unexpected severe structural damages on frame systems or total collapse of structures were reported in many post-earthquake site observations to result from vertical effects of seismic motion. For example, Loma Prieta (1989), Northridge (1994), Kobe (1995), L'Aquila (2009) and NZ sequences (2010, 2011) EQs were known to give rise to severe brittle damages on structural elements due to their high vertical $(\mathrm{H})$-to-horizontal $(\mathrm{H})$ ratios $(\mathrm{V} / \mathrm{H})$.

Due to certain limitations on experimental testing of scaled laboratory model of structures under vertical seismic excitation, many researchers were concentrated on specific numerical and analytical studies as well as field reconnaissance rather than experimental tests. Abdollahiparsa et al. (2016) investigated the effects of vertical earthquake motion on steel frame structures with different story levels considering the SSI and fixed-base case of structures. They proved that vertical earthquake motion and SSI increased the demand of earthquake from structures and could lead to reaching critical capacity range of structural elements. Similar research study on R/C mid-rise building structures under vertical motion was conducted by Abd Rahim et al. (2016) taking into account SSI effect. After the seismic analysis of R/C structures under specified earthquake time-histories with $\mathrm{V} / \mathrm{H}$ ration range of $0.9-1.6$, the need for the consideration of SSI was underlined to better understand the response of structure to vertical earthquake motions. Certain studies were performed on the vertical motion and SSI effects under earthquake ground motion (Azari et al., 2015; Hamid Reza Tabatabaiefar et al., 2014; Tabatabaiefar et al., 2015; Tabatabaiefar et al., 2014; Yu and Liu, 2016). In these studies, two key points were generally stated that (i) vertical earthquake motion and (ii) the SSI directly affected structural behavior of buildings with increase in displacement and sectional forces. Experimental investigation was made to verify and update the advanced soilstructure model proposed by Tabatabaiefar et al. (2014). Using shake table for experimental study, they revealed that the proposed numerical model and modeling considerations were able to accurately predict the influence of SSI effect compared to the fixed base model. A comparative investigation was also done by Bas and Kalkan (2016) performing linear time-history analysis of highrise $\mathrm{R} / \mathrm{C}$ structures under only $\mathrm{H}$ and $\mathrm{H}+\mathrm{V}$ earthquake motion. Based on the comparison, they proved that vertical earthquake motion was not effective on the shear force while the overturning moment under $\mathrm{V}+\mathrm{H}$ loading was obtained four times higher than that under only $\mathrm{H}$ load. Accordingly, many studies in literature including the SSI and vertical earthquake motion effects generally concluded that SSI, vertical earthquake excitation and the combination of them made structure more vulnerable to seismic motion.

With the light of these studies, the effects of vertical earthquake motion on high-rise R/C frame structures are investigated in this study considering SSI and fixed support condition. The main of this investigation is to present the practical outcomes in terms critical structural parameters of the base shear force, overturning moment and base axial force when an earthquake with high $\mathrm{V} / \mathrm{H}$ ratio hits $\mathrm{R} / \mathrm{C}$ frame structures considering the different modeling approaches of fixed support and SSI. For this objective, a typical existing high-rise R/C frame structure designed as per the provisions of TSC (2007) is adopted. The R/C structure is excited by two different load cases, which are only horizontal $(\mathrm{H})$ and horizontal + vertical $(\mathrm{H}+\mathrm{V})$. Comparing the linear time-history analyses (LTHA) results obtained from the SSI and fixed support model for each load case stated above, vertical seismic motion influence is estimated depending on the engineering parameters of the base shear force, base axial force and overturning moment. According to the estimations in the study, this study is also aimed to help those in the field of structural engineering to utilize which modeling technique, SSI or fixed support, is more accurate to regard vertical seismic motion in the design stage of R/C structures.

\section{EARTHQUAKE RECORDS FOR LINEAR TIME-HISTORY ANALYSIS (LTHA)}

The earthquake records shown in Figure 1 are determined based on the $\mathrm{V} / \mathrm{H}$ ratio to clearly indicate the influence of vertical earthquake motion according to the considered engineering parameters. Since reflecting the general features of near-fault effect, 1979 Imperial Valley $\left(M_{w}=6.53\right), 1995$ Kobe $\left(M_{w}=6.90\right)$ and 1999 Kocaeli $\left(M_{w}=7.4\right)$ records are used in the LTHA. In addition, these earthquakes are specifically selected due to leading to non-ductile structural damages observed in the site observations after these earthquakes. General properties of the records are presented in Table 1. Taking into account a limit distance of $15 \mathrm{~km}$ to fault source, the distance to source $(\Delta)$ of the earthquakes is specified within the range of $1.35 \mathrm{~km}-11.0 \mathrm{~km}$ as given Table 1 . As depicted in Figure 1, the earthquake duration of 1999 Kobe EQ is higher than 1979 Imperial Valley EQ and 1999 Kocaeli EQ, respectively. The earthquake ground motions are recorded on soft soil deposits and they are resulted from the strike-slip fault mechanism. General consideration for the number of earthquake records to be utilized in the response history analysis is to use three or seven earthquake motions as stated in ASCE (2010), TSC (2007) and Reyes and Kalkan (2011). Therefore, three earthquake motions are considered in the present study and critical value for the engineering parameters is determined according to max. value of three 
earthquake records. All data of the earthquakes are obtained using the open access database of PEER (2015). As revealed in Figure 2 , frequency response analyses of the earthquakes are also performed to identify effective vibration frequency of horizontal $(\mathrm{H})$ and vertical (V) record. High period range is obtained for horizontal component of all earthquakes and vertical component of Kobe and Kocaeli EQs, but low period range is seen for vertical earthquake component of Imperial Valley EQ as depicted in Figure 2.
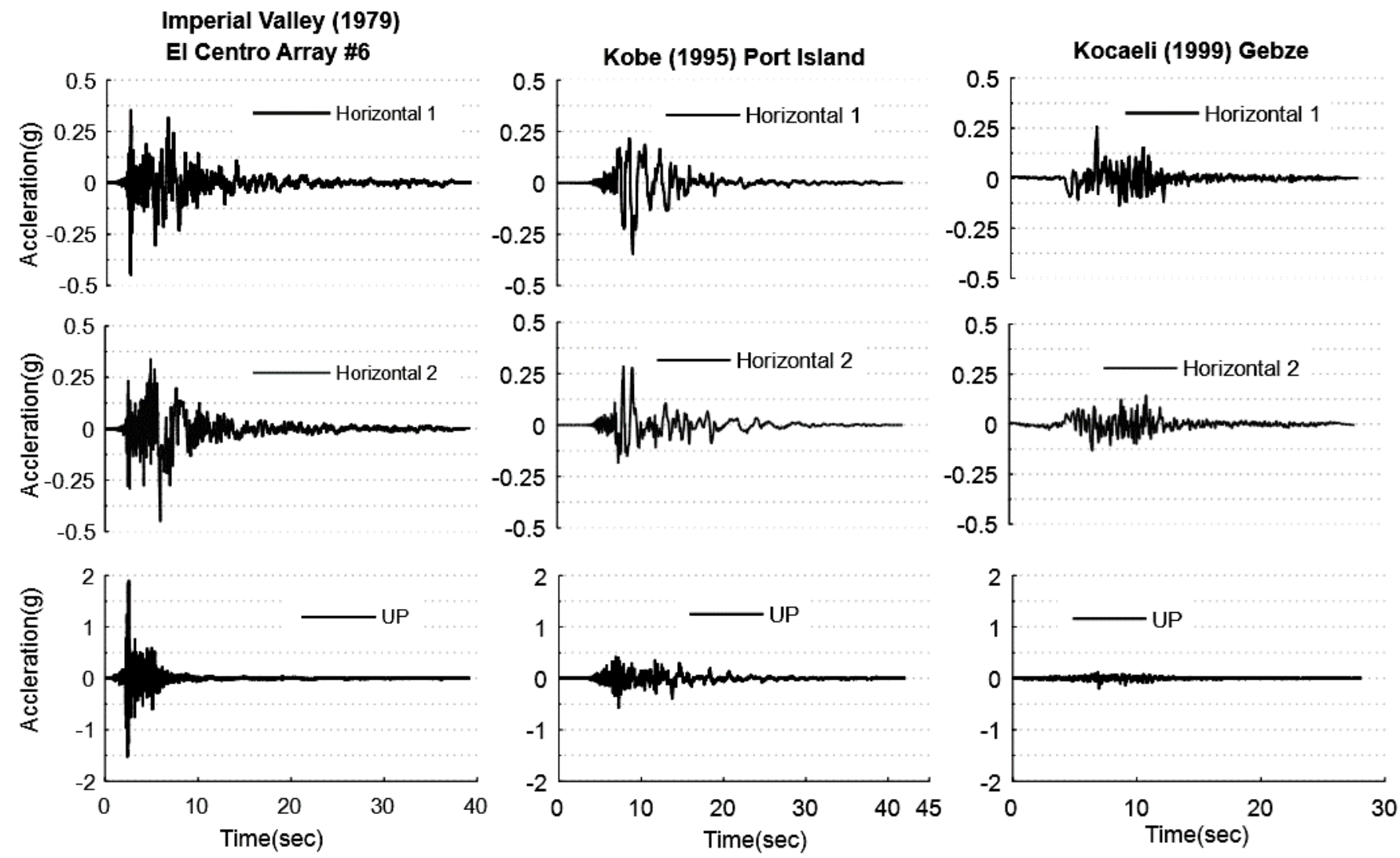

Figure 1. Earthquake records used in the LTHA

Table 1. Properties of the considered earthquakes

\begin{tabular}{ccccccccc}
\hline \multirow{2}{*}{ Year } & \multirow{2}{*}{ Earthquake } & Station & $\Delta$ & \multicolumn{4}{c}{ PGA $(\mathrm{g})$} & \multirow{2}{*}{ V/H } \\
\cline { 5 - 7 } \cline { 5 - 6 } & & & {$[\mathrm{km}]$} & $\mathrm{H}_{1}$ & $\mathrm{H}_{2}$ & $\mathrm{~V}$ & \\
\hline 1979 & Imperial Valley & El Centro Array \#6 & 1.35 & 0.45 & 0.44 & 1.90 & 4.31 \\
1995 & Kobe & Port Island & 3.31 & 0.35 & 0.29 & 0.57 & 1.96 \\
1999 & Kocaeli & Gebze & 10.92 & 0.26 & 0.14 & 0.19 & 0.73 \\
\hline
\end{tabular}

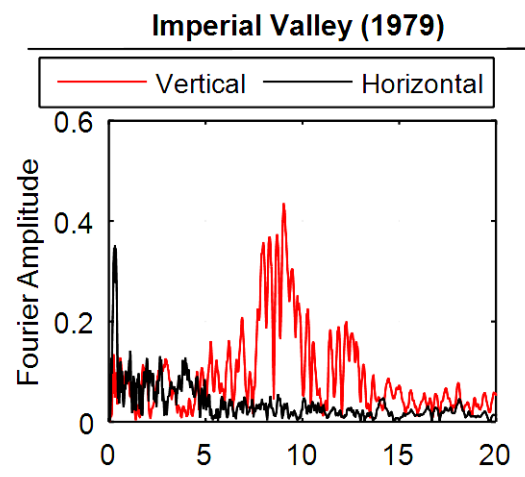

Kobe (1995)

Kocaeli (1999)

Figure 2. Frequency contents of the earthquake records 


\section{NUMERICAL FE MODEL OF R/C STRUCTURE AND SIOL ZONE FOR SSI}

\subsection{FE Model of the R/C Structure and Modeling Considerations}

Structural model for the LTHA is selected as existing high-rise R/C semi-ductile system having shear wall and column-beam frames. As shown in Figure 3(b), the height of the structure with ten stories is $45.0 \mathrm{~m}$, and the story height is $4.5 \mathrm{~m}$. The test structure is designed according to specifications of TSC (2007). The same floor plan for each story is given in Figure 3(a). All columns and shear walls are located on the plan symmetrically, and no cantilever elements are considered in the project of the structure. Therefore, no irregularity condition is defined for the structure. More details related to design and analysis of the structure are summarized in Table 2 .

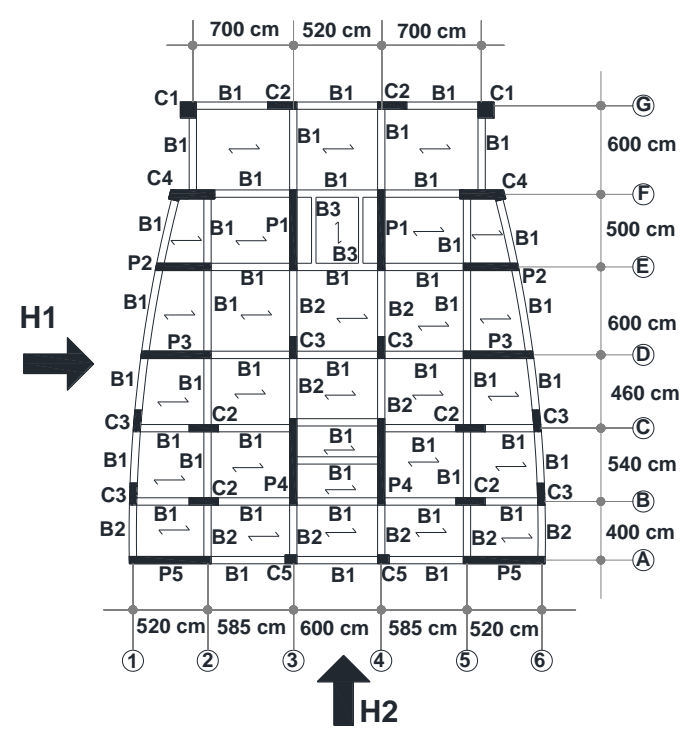

(a)

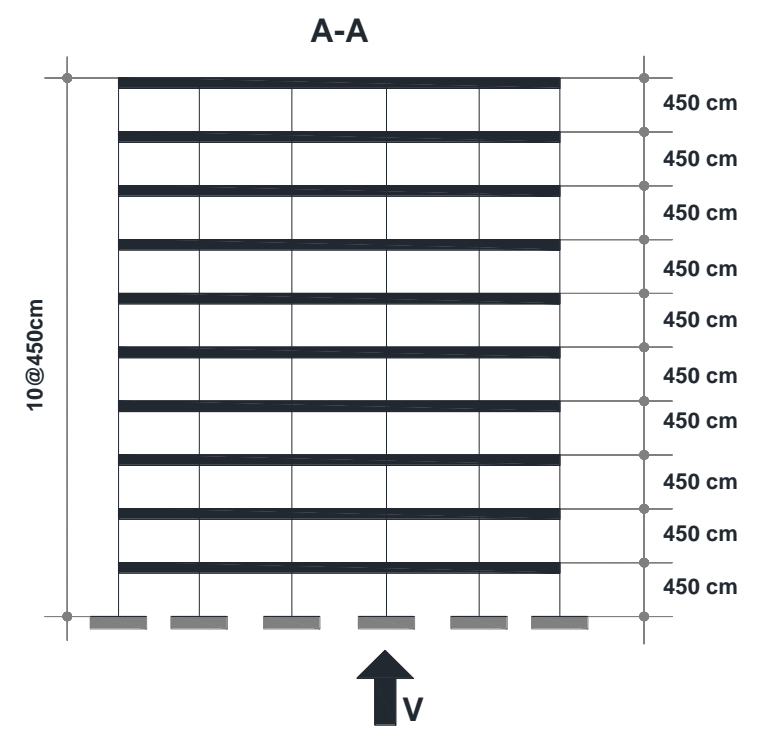

(b)

Figure 3. (a) Floor plan (b) Elevation of test structure

Table 2. General properties of the test structure

\begin{tabular}{|r|l|}
\hline Number of stories: & 10 \\
\hline Story height $(\mathrm{m}):$ & 4.5 \\
\hline Occupation type: & Municipality \\
\hline Structural system: & Shear-wall-frame $(R=7)$ \\
\hline Concrete grade: & $\mathrm{C} 35\left(f_{c k}=30 \mathrm{MPa}\right)$ \\
\hline Reinforcement grade: & $\mathrm{S} 420\left(f_{y k}=420 \mathrm{MPa}\right)$ \\
\hline Live load participation factor $(n):$ & 0.3 \\
\hline Dead and Live load: & 7.50 and $5.0 \mathrm{kN} / \mathrm{m}^{2}$ \\
\hline Total mass $=10 \mathrm{x}$ floor mass: & $10 \mathrm{x} 1342.6($ ton $)=13426($ ton $)$ \\
\hline Seismic zone: & $1^{\text {st }}\left(A_{0}=0.4\right)$ \\
\hline Importance factor $(I):$ & 1.5 \\
\hline Type of the ground: & $\mathrm{Z} 3\left(T_{a}=0.15 \mathrm{~s}, T_{b}=0.60 \mathrm{~s}\right)$ \\
\hline
\end{tabular}

Considering the complementary properties of the test structure, FE model of the R/C building is established using SAP2000 (2015) structural analysis software. For this aim, columns and beams are modeled as frame element. Shell element is assigned to slab and shear wall, and for the mat foundation with the height of $1.0 \mathrm{~m}$, plate element is defined. Rigid diaphragm condition is considered for each different level story of the structure, which is necessary to safely transfer earthquake load to other frames and to provide no to be out-of-plane response of concrete slab. The completed FE model of the structure and its 3-D view are shown in Figures 4(a)-4(b), respectively. 


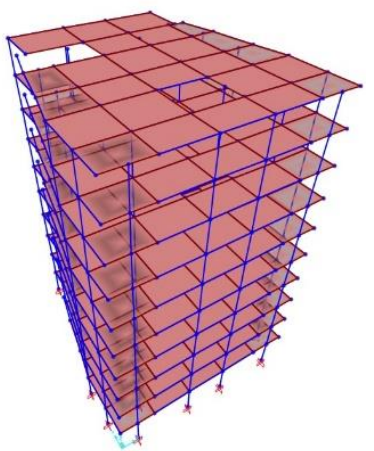

(a)

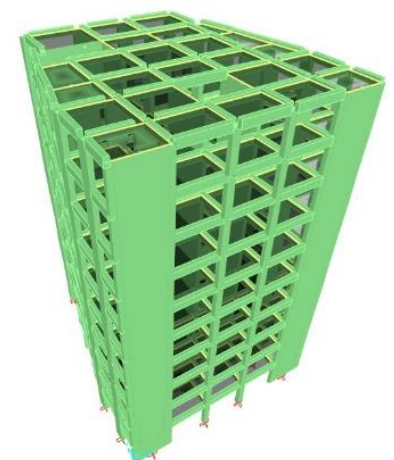

(b)

Figure 4. (a) FE model (b) 3-D view of the structure

\subsection{FE Model of Soil Medium and SSI Method}

Soil zone under the foundation has infinite dimensions in reality, but finite element soil zone can be considered when properly reflecting the boundary condition around the separated surface of infinite soil zone. Modeling of soil zone is directly dependent on SSI method to be adopted. In literature, the SSI methods are regarded as two approaches: (i) Direct Method (ii) Substructure Method (Aydemir and Ekiz, 2013; Aydinoğlu, 993; Far, 2017; Lou et al., 2011; Lysmer and Kuhlemeyer, 1969).In the direct method, soil and structure are modeled together, and coupled response is thus taken into account. The substructure method is based on assumption that soil and structure are modeled separately and coupled effect is considered indirectly. More details for these methods are given in the study of Aydinoğlu (1993). The equation of motions proposed for dynamic soil-structure-interaction and solving these equations are considerably complex. General governing equation of motion for SSI is as given in Eq. (1).

$$
[M]\{\ddot{x}\}+[C]\{\dot{x}\}+[K]\{x\}=-[M]\left\{\ddot{x}_{g}\right\}+\left\{F_{V}\right\}
$$

where, $\{\ddot{x}\}$ : acceleration, $\{\dot{x}\}$ : velocity and $\{x\}$ : nodal displacements of the common nodal points between foundation and top level surface of soil medium. $[M],[C]$ and $[K]$ are the mass matrix, the damping matrix and stiffness matrix, respectively. $\left\{\ddot{x}_{g}\right\}$ : the earthquake excitation acceleration and $\left\{F_{V}\right\}$ : force vector resulting from the boundary condition. Since the direct method enables to develop a unified soil-structure FE model, the equation of the motion can be solved only with estimating nearfield effects. In this study, direct method is adopted for SSI, and the main composing elements of structure, common nodes, soil foundation system and earthquake excitation at the bedrock level are depicted in Figure 5.

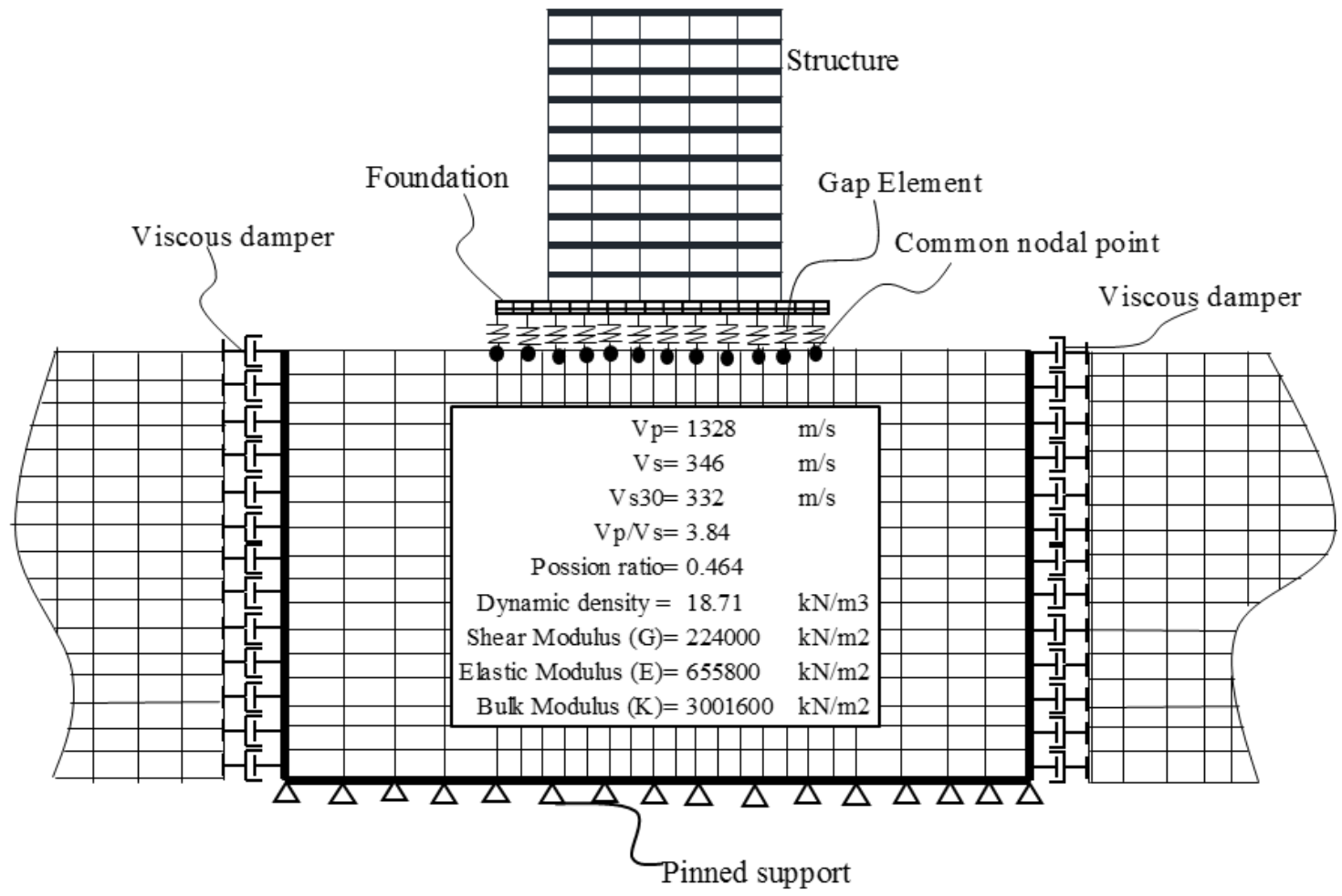

Figure 5. Schematic representation of FE modeling for SSI with transmitting boundaries 


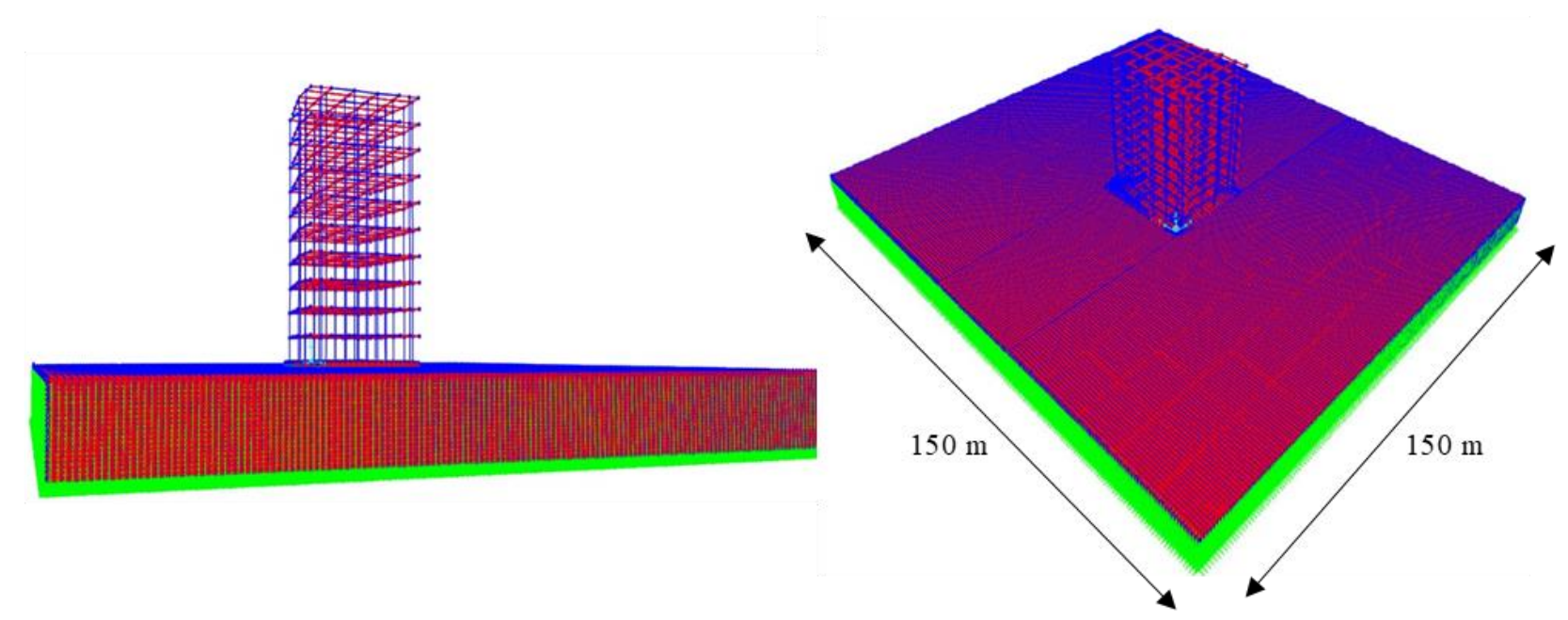

Figure 6. Entire FE model of the soil-structure system through direct method

According to the direct method, the far-field effect of unbounded infinite soil medium is tried to be reflected by the boundary conditions: (i) free boundaries (ii) tied boundaries and (iii) transmitting boundaries (viscous boundary) (Aydinoğlu, 1993; Manafpour and Moradi, 2012). Thus, the soil medium in the current study is established as elastic solid element considering the parameters of Standard Penetration Test (SPT) results. For the interface between the near-field and far-field, viscous dampers are used in the vertical and horizontal direction as revealed in Figure 5, and damping coefficient is calculated with Eq. (2) proposed by Lysmer and Kuhlemeyer (1969). In this finite modeling method of soil media, they revealed that the infinite media might be considered as two parts: the near field and far field. The soil part corresponding to near-field should be considered directly modeling the soil while the rest of the infinite soil media could not be included in the model provided that a transmitting soil interface as shown in Figure 5 was defined and damper far-field were assigned to all points on this interface utilizing Eq. (2). Based on these modeling considerations, the entire FE model of the soil structure is established as shown in Figure 6. In the FE model, the dimension of the bounded soil media is assumed as $150 \mathrm{mx} 150 \mathrm{~m}$ that is five times of the dimensions of the mat foundation of the structure.

$$
C_{h}=-\rho \cdot V_{p} \cdot A ; C_{v}=-\rho \cdot V_{s} \cdot A
$$

where, $C_{h}$ : horizontal viscous damping coefficient, $C_{v}$ : vertical viscous damping coefficient, $V_{p}$ : compressive shear wave velocity and $V_{s}$ : shear wave velocity, $A=$ effective nodal area and $\rho=$ mass density.

\section{LINEER TIME-HISTORY ANALYSIS (LTHA)}

In order to compare the results from the SSI with those from the FS model, the linear-time history analysis (LTHA) is performed in this study. For this aim, Rayleigh damping ratio calculated according to the modal damping ratio of $\% 5$ is considered for the test structure. This value is taken as $4.5 \%$ for the soil media modeled with solid elements. Besides, the non-linear dead-load analysis is also done as an initial condition for the LTHA. Thus, the dead-load deformed shape is considered for the LTHA, which gives rise to a change in the stiffness matrix of the structural system. For more accurate results, 50 modes are also taken into consideration for the LTHA. Specifically selected earthquake records as shown in Figure 1 are applied to the SSI model at the bedrock level. Therefore, the displacement time-histories of the records considered are used for this model instead of the acceleration timehistories that are used in the FS model.

As depicted in Figure 7, no change in the base shear force during earthquake is obtained as expected before the analysis of SSI model. This result is mostly based on that the base shear force is more sensitive to horizontal components of earthquake than that of vertical component. As a result, vertical earthquake motion is concluded not to be effective on the base shear force. The percentage change in the base shear force is also given in Table 3. In order to determine the influence of the SSI model with soil on the fixed support model (FS) with no soil, these models having different modeling approach are compared for $\mathrm{H}$ and $\mathrm{H}+\mathrm{V}$ load conditions. The SSI model is estimated from the comparison to result in higher base shear value than the FS model regardless of loading condition. Hence, it is recommended to utilize the SSI model instead of FS model to make reliable seismic design of building structures. When it comes to percentage change in the base shear force according to the earthquakes, Kobe and Kocaeli EQs give higher percentage value from Imperial Valley EQ. The high change is estimated with close frequency values of them to the natural vibration frequency of the $\mathrm{R} / \mathrm{C}$ building. 

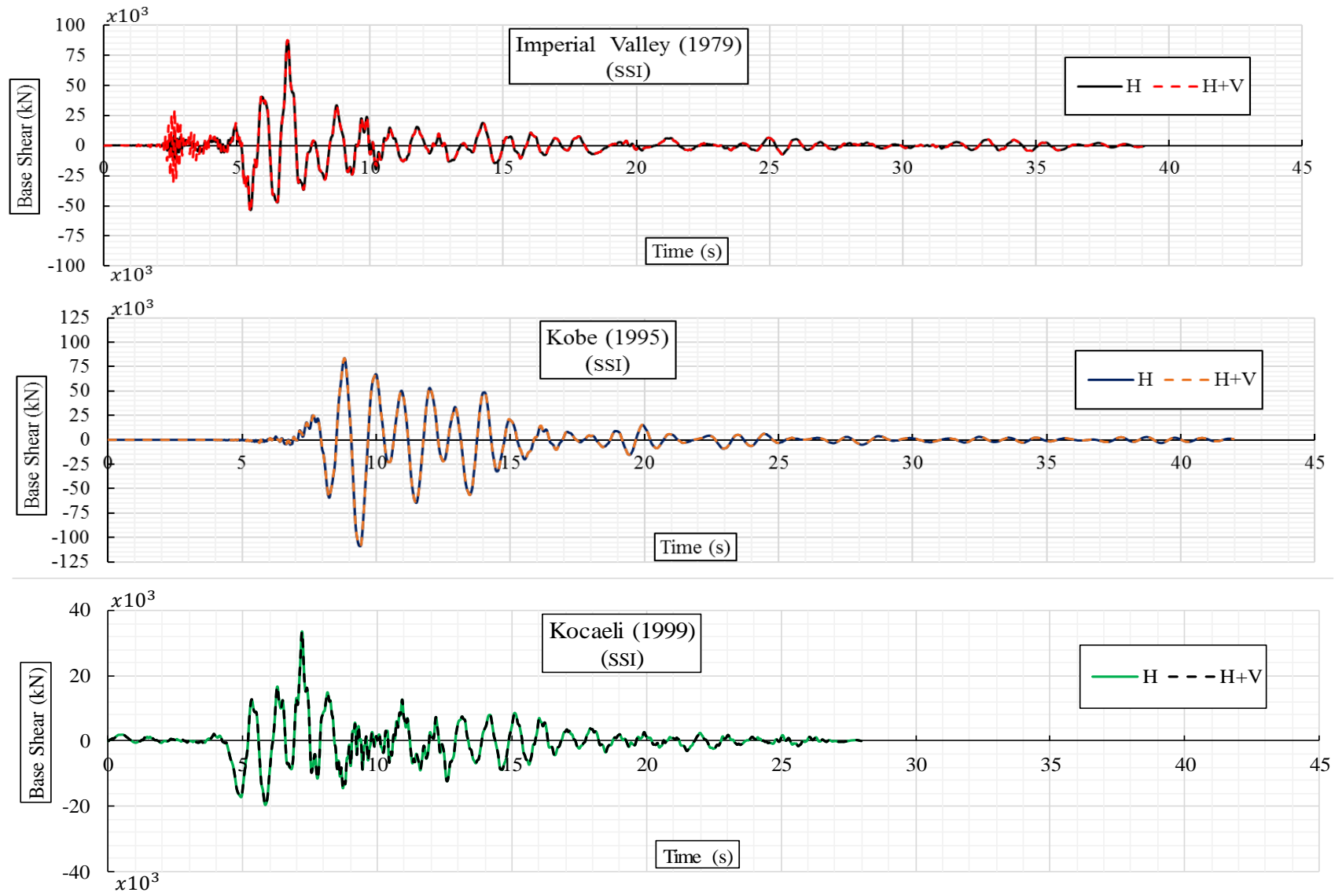

Figure 7. Variation of the base shear force of the SSI model in earthquake duration
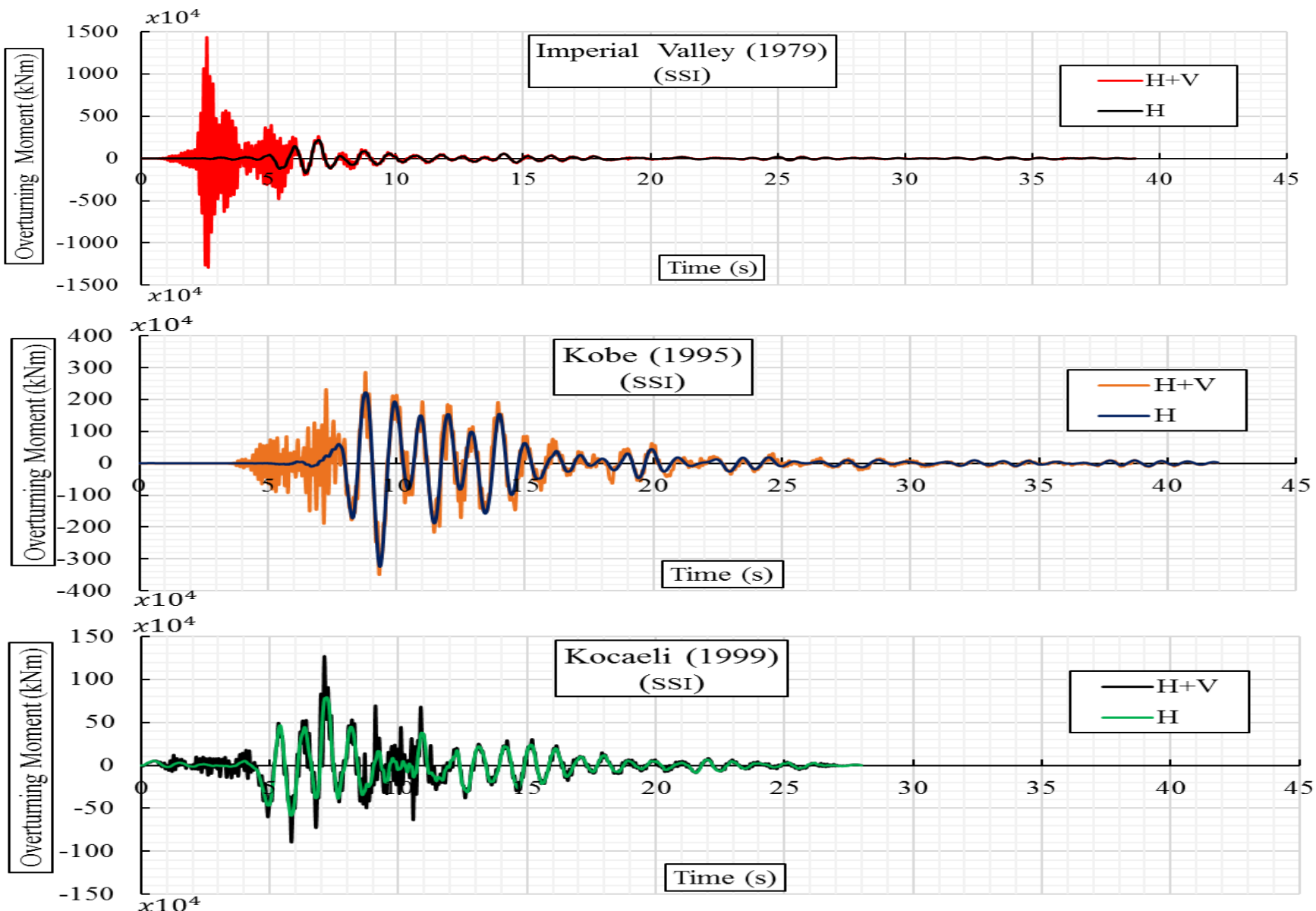

Figure 8. Variation of the overturning moment of the SSI model in earthquake duration 


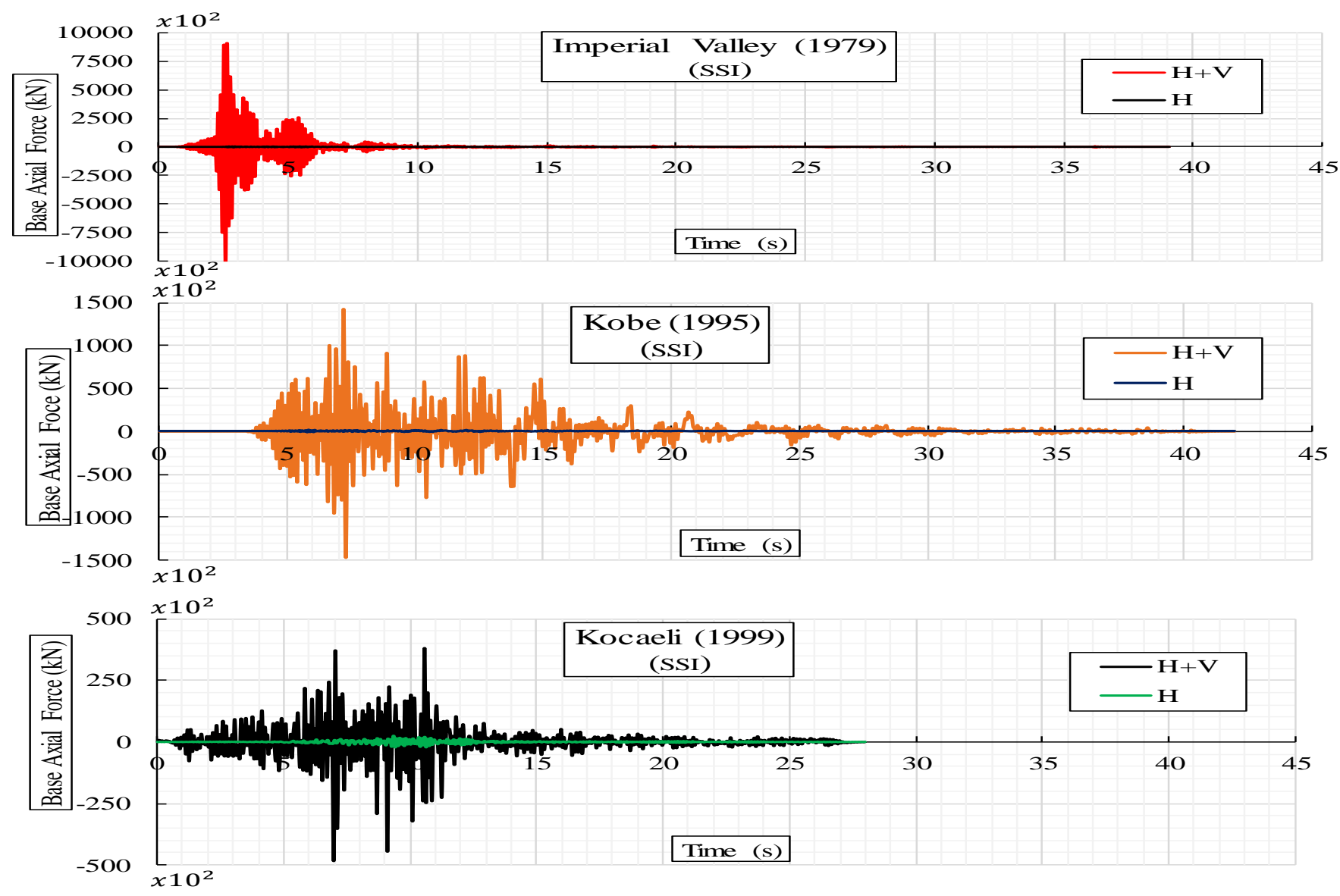

Figure 9. Variation of the base axial force of the SSI model in earthquake duration

Table 3. Max. percentage change value in the engineering parameters

\begin{tabular}{|c|c|c|c|c|}
\hline \multicolumn{5}{|c|}{ Base Shear Force $(\mathrm{kN})$} \\
\hline \multirow[b]{2}{*}{ EQs } & $\mathrm{H}$ & $\mathrm{H}+\mathrm{V}$ & \multicolumn{2}{|c|}{ Change $\%(\mathrm{H}+\mathrm{V} / \mathrm{H})$} \\
\hline & $\begin{array}{c}\text { Change } \\
\% \text { (SSI-FS) }\end{array}$ & $\begin{array}{c}\text { Change } \\
\% \text { (SSI-FS) }\end{array}$ & $\%(\mathrm{FS})$ & $\%(\mathrm{SSI})$ \\
\hline Imperial Valley & 4 & 4 & 0.0 & 0.3 \\
\hline Kobe & 61 & 62 & -0.2 & 0.5 \\
\hline Kocaeli & 28 & 28 & 0.0 & 0.1 \\
\hline \multicolumn{5}{|c|}{ Overturning Moment (kNm) } \\
\hline \multirow[b]{2}{*}{ EQs } & $\mathrm{H}$ & $\mathrm{H}+\mathrm{V}$ & \multicolumn{2}{|c|}{ Change $\%(\mathrm{H}+\mathrm{V} / \mathrm{H})$} \\
\hline & $\begin{array}{c}\text { Change } \\
\% \text { (SSI-FS) }\end{array}$ & $\begin{array}{c}\text { Change } \\
\% \text { (SSI-FS) }\end{array}$ & $\%(\mathrm{FS})$ & $\%$ (SSI) \\
\hline Imperial Valley & -7 & 52 & 301 & 554 \\
\hline Kobe & 61 & 47 & 21 & 10 \\
\hline Kocaeli & -91 & -86 & 9 & 60 \\
\hline \multicolumn{5}{|c|}{ Base Axial Force $(\mathrm{kN})$} \\
\hline \multirow[b]{2}{*}{ EQs } & $\mathrm{H}$ & $\mathrm{H}+\mathrm{V}$ & \multicolumn{2}{|c|}{ Change $\%(\mathrm{H}+\mathrm{V} / \mathrm{H})$} \\
\hline & $\begin{array}{c}\text { Change } \\
\% \text { (SSI-FS) }\end{array}$ & $\begin{array}{c}\text { Change } \\
\% \text { (SSI-FS) }\end{array}$ & $\%(\mathrm{FS})$ & $\%(\mathrm{SSI})$ \\
\hline Imperial Valley & 427 & 55 & 71786 & 21095 \\
\hline Kobe & 811 & 54 & 69176 & 11584 \\
\hline Kocaeli & 1038 & 52 & 14587 & 1856 \\
\hline
\end{tabular}


Unlike to the base shear force, the overturning moment is highly affected from the consideration of vertical seismic motion as shown in Figure 8. In all earthquakes, the higher overturning moment values are estimated for both $\mathrm{H}$ and $\mathrm{H}+\mathrm{V}$ load cases, but those obtained from $\mathrm{H}+\mathrm{V}$ analysis are higher than that from $\mathrm{H}$ analysis. In addition, the overturning moment estimation is done using SSI model instead of FS model due to noticeable increase in SSI model. According to results given Table 3, the percentage increase in the overturning moment is determined compatible with the $\mathrm{V} / \mathrm{H}$ ratio. Considerable increase in the overturning moment is predicted that vertical load bearing elements such as, columns and piers need to more strength capacity in terms of bending moment. In other words, the flexural strength capacity of these structural elements should be considered as high when vertical earthquake excitation will adopted in the analysis.

As predicted before the LTHA, the highest increase among the other parameters is obtained in the base axial force. The variation of the base axial force is demonstrated in Figure 9, and the value of this change is given in Table 3 in terms of percentage for each earthquake. However, the percentage increase is resulted as higher under $\mathrm{H}$ load than $\mathrm{H}+\mathrm{V}$, which means that vertical seismic motion treated as balancing effect. Similarly, the SSI model is obtained to give lower results than FS model. This lower change is directly pertinent to damping properties of the soil media. In the current study, the bounded soil media as given in Figure 6 is developed taking into account elastic soil with $4 \%$ damping ratio. With the relatively high increase in the base axial force, current axial force capacity of columns and piers at the $1^{\text {st }}$ floor, which was designed according to only $\mathrm{H}$ load, is estimated not to provide sectional axial force demand from the earthquakes for both the SSI model and H+V load case.

\section{SUMMARY AND CONCLUSIONS}

In the present investigation, the consideration of the vertical earthquake motion is studied through the comparison of the base shear force, base axial force and overturning moment between only horizontal earthquake motion $(\mathrm{H})$ and horizontal + vertical earthquake motion $(\mathrm{H}+\mathrm{V})$ for each modeling assumption of soil-structure-interaction (SSI) and fixed support condition (FS). After selecting well-known earthquake motions that reflects the effects of near-field earthquake according to vertical-to-horizontal-ratio (V/H) in terms of max. acceleration, FE model of high-rise R/C test structure is developed using different element and connection models of frame, shell, plate, gap, link and damper. Similar efforts are also made for developing SSI model including soil medium according to the SSI method. One of the SSI methods, the Direct Method, is adopted for this aim by modeling structure and infinite soil zone all together that also provides to consider the couple effect on considered engineering parameters. For the modeling soil zone, transmitting boundary condition is used and modeled as damper element according to the soil parameter obtained from the fieldtest of SPT. Pinned support connection is assigned to the nodes at the bedrock level where earthquake motion is applied. Based on these considerations related to modeling and method, the linear time-history analysis (LTHA) of the test structure is performed, and the results from the LTHA are presented in comparative manner for the considered engineering parameters. Thus, following main practical outputs are given below,

$>$ As expected, no change in the base shear force under H+V load is obtained for the SSI and FS models, which means that vertical earthquake motion is not effective on this parameter. Therefore, no failure/damage, such as shear failure is not estimated on vertical load bearing elements upon considering vertical earthquake motion. When comparing the SSI model and FS model, the SSI model yields to higher results than FS model. So, structural design is recommended to be made utilizing the SSI model instead of the FS model.

$>$ Higher overturning moment values are estimated for both $\mathrm{H}$ and $\mathrm{H}+\mathrm{V}$ load cases, but those obtained from $\mathrm{H}+\mathrm{V}$ analysis are higher than that from $\mathrm{H}$ analysis. The percentage increase in the overturning moment is determined compatible with the $\mathrm{V} / \mathrm{H}$ ratio. The overturning moment estimation is recommended to be performed using SSI model instead of FS model due to noticeable increase in SSI model. Considerable increase in the overturning moment is predicted that vertical load bearing elements such as, columns and piers need to more strength capacity in terms of bending moment.

$>$ The highest increase among the other parameters is obtained in the base axial force. However, the percentage increase is resulted as higher under $\mathrm{H}$ load than $\mathrm{H}+\mathrm{V}$, which means that vertical seismic motion treated as balancing effect. This lower change under $\mathrm{H}+\mathrm{V}$ load case is directly pertinent to damping properties of the soil media. Therefore, design of columns and piers against axial force is recommended to be made for more safety according to the outcomes from the FS model.

Based on these conclusions, the effects of dimensions of the bounded soil media on the analyses results can estimated considering different dimensions instead of that in the current study. General estimations can be made by repeating the LTHA according to different soil types. For more realistic damage analyses, non-linear direct time-integration response history analysis of the test structure is recommended to be conducted.

\section{REFERENCES}

Abd Rahim. SM., Mohd Zahid, MZA., Wan Omar, WMS., Bin Ab Rahim, MA. \& Faisal, A. (2016). Assessment of reinforced concrete building with soil structure interaction effect under vertical earthquake. In: Materials Science Forum, Kaohsiung, Taiwan, 2016. pp 331-336. doi:10.4028/www.scientific.net/MSF.857.331 
Abdollahiparsa, H., Homami, P., Khoshnoudian, F. (2016). Effect of vertical component of an earthquake on steel frames considering soil-structure interaction. KSCE Journal of Civil Engineering, 20, 2790-2801. doi:10.1007/s12205-016-0687-y

ASCE (2007). Seismic rehabilitation of existing buildings, ASCE/SEI 41-06. American Society of Civil Engineers, Reston, VA

ASCE (2010). Minimum design loads for buildings and other structures, ASCE/SEI 7-10. American Society of Civil Engineers, Reston, VA.

ASCE (2014). Seismic rehabilitation of existing buildings, ASCE/SEI 41-13. American Society of Civil Engineer, Reston, VA.

Aydemir, ME. \& Ekiz, I. (2013). Soil-structure interaction effects on seismic behaviour of multistorey structures. European Journal of Environmental and Civil Engineering, 17, 635-653. doi:10.1080/19648189.2013.810177

Aydinoğlu, MN. (1993). Consistent formulation of direct and substructure methods in nonlinear soil-structure interaction. Soil Dynamics and Earthquake Engineering, 12, 403-410. doi:https://doi.org/10.1016/0267-7261(93)90003-A

Azari, B., Fatahi, B. \& Khabbaz, H. (2015). Numerical analysis of vertical drains accelerated consolidation considering combined soil disturbance and visco-plastic behaviour. Geomechanics and Engineering 8, 187-220. doi:10.12989/gae.2015.8.2.187

Bas, S. \& Kalkan, I. (2016). The effects of vertical earthquake motion on an R/C structure. Structural Engineering and Mechanics 59, 719-737. doi:10.12989/sem.2016.59.4.719

Eurocode-8 (1998). Design provisions for earthquake resistance of structures - Part 5: Foundations, retaining structures and geotechnical aspects. CEN European Committee for Standardization, Brussel, Belgium.

Far, H. (2017). Advanced computation methods for soil-structure interaction analysis of structures resting on soft soils. International Journal of Geotechnical Engineering, 1-8. doi:10.1080/19386362.2017.1354510

Hamid Reza Tabatabaiefar, S., Fatahi, B., Samali, B. (2014). An empirical relationship to determine lateral seismic response of mid-rise building frames under influence of soil-structure interaction. The Structural Design of Tall and Special Buildings, 23, 526-548. doi:doi:10.1002/tal.1058

IS:1893 (2000). Indian standard criteria for earthquake resistant design of structures. New Delhi, India.

Lou, M., Wang, H., Chen, X., \& Zhai, Y. (2011). Structure-soil-structure interaction: literature review. Soil Dynamics and Earthquake Engineering, 31, 1724-1731. doi:https://doi.org/10.1016/j.soildyn.2011.07.008

Lysmer, J. \& Kuhlemeyer, RL. (1969). Finite dynamic model for infinite media. Journal of the Engineering Mechanics Division (ASCE), 95, 859-878

Manafpour, AR., Moradi, V. (2012). Investigating conventional FE modelling for dynamic soil-structure interaction under horizontal and vertical ground motions. In: The 15th World Conference on Earthquake Engineering, Lisbon, Portugal.

NBC105 (1994). Nepal national building code. Ministry of Physical Planning and Works Department of Urban Development and Building Construction, Babar Mahal, Kathmandu, Nepal.

NZS1170.5 (2004). Structural Design Actions Part 5: Earthquake Actions-New Zealand Standards

PEER (2015) The Pacific earthquake engineering research center ground motion database, Berkeley, CA

Reyes, JC. \& Kalkan, E. (2011). Required number of records for ASCE/SEI 7 ground-motion scaling procedure. U.S. Geological Survey, US.

SAP2000 (2015). SAP 2000 v17.2 Integrated finite element analysis and design of structures. Computers and Structures Inc, Berkeley, CA.

Tabatabaiefar, HR., Fatahi, B., Ghabraie, K. \& Zhou, W-H. (2015). Evaluation of numerical procedures to determine seismic response of structures under influence of soil-structure interaction. Structural Engineering and Mechanics, 56, 27-47.

Tabatabaiefar, SHR., Fatahi, B. \& Samali, B. (2014). Numerical and experimental investigations on seismic response of building frames under influence of soil-structure interaction. Advances in Structural Engineering, 17, 109-130. doi:10.1260/13694332.17.1.109 
TSC (2007). Specification for buildings to be built in earthquake zones. Ministry of Public Work and Settlement, Ankara, Turkey UBC (1997). Uniform Building Code, US

Yu, J. \& Liu, X. (2016). The influence of vertical ground motion on the seismic behavior of RC frame with construction joints. Earthquake and Structures, 11, 407-420. doi:10.12989/eas.2016.11.3.407 